\title{
PROPOSITION OF ABRASION RESISTANCE DETERMINING METHOD OF MATERIALS USED FOR PRODUCTION OF PLOWSHARES
}

\author{
Andrzej Borawski ${ }^{1}$, Dariusz Szpica ${ }^{1}$, Grzegorz Mieczkowski $^{1}$, Mohamed M. Awad ${ }^{2}$, \\ Rizk M. Shalaby ${ }^{2}$, Mohammed Sallah ${ }^{2,3}$ \\ ${ }^{1}$ Bialystok University of Technology, Poland; ${ }^{2}$ Mansoura University, Egypt; \\ ${ }^{3}$ Higher Institute for Engineering and Technology, Egypt \\ a.borawski@pb.edu.pl,d.szpica@pb.edu.pl,g.mieczkowski@pb.edu.pl,m_m_awad@mans.edu.eg, \\ rizk2002@mans.edu.eg, msallahd@mans.edu.eg
}

\begin{abstract}
The development of the agricultural industry is aimed, among others, at a significant increase in the field area being processed by individual farmers. As the farmland that needs to be processed is getting bigger and the time to perform the work has not changed, it is necessary to constantly increase the efficiency of agricultural machinery. This fact requires the use of innovative solutions and materials that will meet the task given to them. One of the hardest working machines are plows. Their main parts are introduced to dynamic, complex states of stress. Among many of its components, there is the material shear stress caused by friction of the share against the soil. The material used for the production of this part (usually one of the steel grades) must, inter alia, have good abrasion resistance. This work proposes a quick and relatively cheap method of checking/comparing material/materials in terms of their resistance to abrasive wear. For this purpose, the so-called ball-cratering method was used, which consists measuring micro-wear in the sample-ball contact. By using this method, it is also possible to test modified surfaces, e.g., coated or toughened. As the name suggests, it is a very precise method, so it is necessary to correctly select the input parameters. To meet this requirement, the Taguchi process optimization method was used. By using the developed method, good accuracy and repeatability of results could be obtained, which is extremely important in research processes.
\end{abstract}

Keywords: plowshares material; ball-cratering; Taguchi method.

\section{Introduction}

The basic cultivation procedure in plowing technology is plowing, and special importance is attached to pre-winter plowing (finches) performed in the autumn under spring plants.

Currently, it is recommended that the field after pre-winter plowing should be as even as possible. The point is that the field surface should have a relatively similar humidity, which will allow the soil to heat and dry in the same way in spring [1]. The agrotechnical guidelines for deep plowing recommend that it should be carried out always to the depth of the entire thickness of the soil before the planned cultivation of root crops. One of the most important criteria of great importance for the quality of deep plowing is the selection of the mouldboard type in the plow in use [2].

The distribution of the forces occurring during plowing is complex, and often modern equipment is used to measure them [3], also mathematical modelling is popular these days [4]. Much depends on the geometry of the contact [5]. The type of materials used is also important [6;7]. It is well known that the value of the friction coefficient and wear rate coefficient will vary depending on the associated materials of the friction pair. Reducing the friction of the soil against the surface of openwork mouldboards or reducing the resistance of the soil moving along the mouldboards and plowshares may reduce fuel consumption by up to $20 \%$ [8-10].

Choosing the right material in structures is not always easy. Often a series of tests is done before making a final decision. This paper presents a proposal for a quick and cheap method for determining the essential properties (i.e. abrasive wear rate coefficient) of the materials used for the production of plow blades. The tests are comparative and allow to evaluate the necessary material properties.

\section{Materials and methods}

The method of micro-abrasive wear called ball-cratering was used for the tests. For this purpose, the T-20 test stand (Figure 1) was used, which enables the measurement of many parameters. The test object consisted of a total of 30 cylindrical samples: 15 samples made of B27 steel, and 15 samples made of $27 \mathrm{MnCrB5}-2$ steel. The material was selected based on availability. The couter-sample of the test objects was a ball with a diameter of 1 " $(25.4 \mathrm{~mm})$ made of $17 \mathrm{HNM}$ steel, which rotated against the sample causing its wear. As a result, a crater was formed, the measurement of which allows to determine several tribological properties of the sample (including the material frictional wear rate coefficient). 


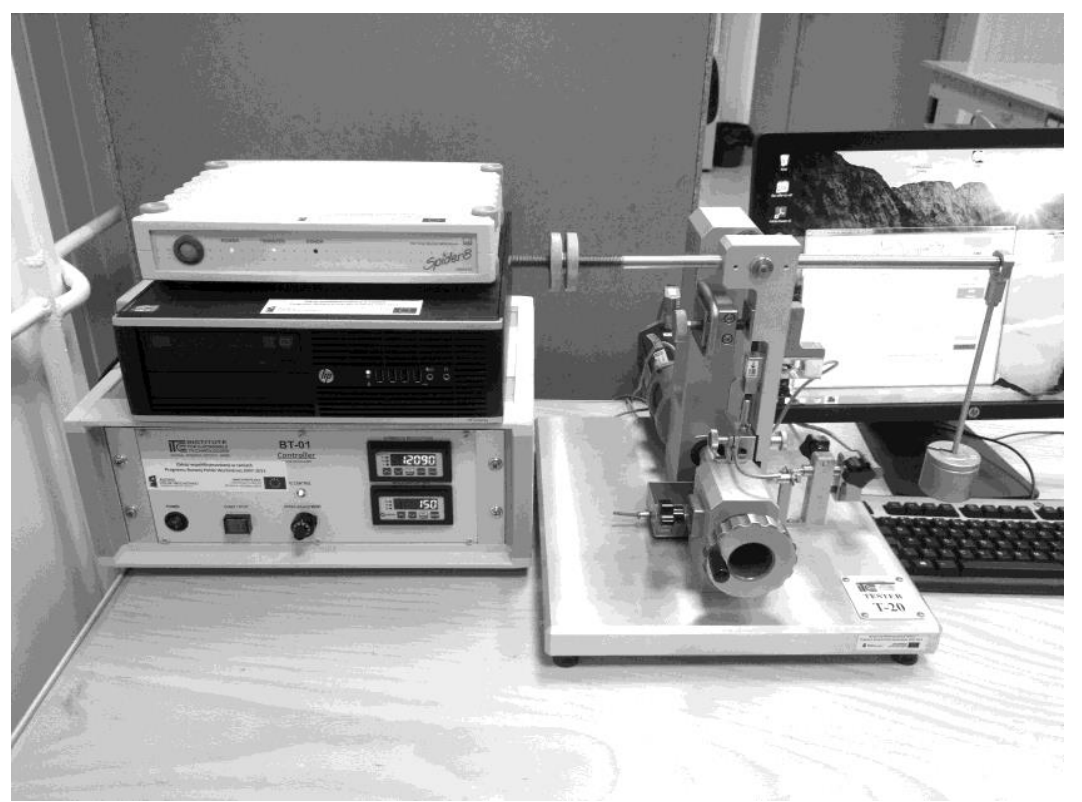

Fig. 1. Test stand

In this type of research, it is necessary to set appropriate boundary conditions, namely: ball rotational speed, friction path and clamping force. The correct selection of the values of the above parameters is of key importance for the correctness and repeatability of the results. For this purpose, the Taguchi process optimization method was used among the many available methods. It is a commonly used method of planning an experiment in this type of research.

The first step in planning was to perform preliminary examinations. The obtained results made it possible to initially estimate for which ranges of input parameters satisfactory crater sizes were obtained. They also enabled the development of an orthogonal table (Table 1), on the basis of which the preliminary research was performed [11].

Table 1

\section{Orthogonal table of preliminary research}

\begin{tabular}{|c|c|c|c|}
\hline $\begin{array}{c}\text { Preliminary } \\
\text { research No. }\end{array}$ & Load, N & $\begin{array}{c}\text { Friction } \\
\text { length, m }\end{array}$ & $\begin{array}{c}\text { Ball rotation } \\
\text { speed, RPM }\end{array}$ \\
\hline 1 & 0.2 & 50 & 38 \\
\hline 2 & 0.2 & 100 & 80 \\
\hline 3 & 0.2 & 150 & 150 \\
\hline 4 & 0.4 & 50 & 80 \\
\hline 5 & 0.4 & 100 & 150 \\
\hline 6 & 0.4 & 150 & 38 \\
\hline 7 & 0.6 & 50 & 38 \\
\hline 8 & 0.6 & 100 & 150 \\
\hline 9 & 0.6 & 150 & 80 \\
\hline
\end{tabular}

Each of the nine studies was performed three times. The results of measurements of crater diameters, which allowed for the calculation of relative errors and ETA function, are summarized in Table 2. The final test result was the arithmetic mean. The standard deviation for each measurement, calculated from the relationship, is also given below:

$$
s=\sqrt{\frac{1}{n-1} \cdot \sum_{i=1}^{n}\left(x_{i}-\bar{x}\right)^{2}},
$$

where $s$-standard deviation;

$S$ - number of measurments. 
Preliminary research results

\begin{tabular}{|c|c|c|c|c|c|}
\hline $\begin{array}{c}\text { Test } \\
\text { No. }\end{array}$ & $\begin{array}{c}\text { Measuring } \\
\text { surface }\end{array}$ & $\begin{array}{c}\text { Test result } \\
\text { No. 1, mm }\end{array}$ & $\begin{array}{c}\text { Test result } \\
\text { No. 2, mm }\end{array}$ & $\begin{array}{c}\text { Test result } \\
\text { No. 3, mm }\end{array}$ & $\begin{array}{c}\text { Arithmetic } \\
\text { mean }\end{array}$ \\
\hline \multirow{2}{*}{1} & Vertical & 0.42 & 0.54 & 0.57 & $0.51 \pm 0.08$ \\
& Horizontal & 0.43 & 0.57 & 0.57 & $0.52 \pm 0.08$ \\
\hline \multirow{2}{*}{2} & Vertical & 0.61 & 0.58 & 0.44 & $0.54 \pm 0.09$ \\
& Horizontal & 0.53 & 0.59 & 0.57 & $0.56 \pm 0.03$ \\
\hline \multirow{2}{*}{3} & Vertical & 0.47 & 0.43 & 0.51 & $0.47 \pm 0.04$ \\
& Horizontal & 0.49 & 0.44 & 0.53 & $0.49 \pm 0.05$ \\
\hline \multirow{2}{*}{4} & Vertical & 0.69 & 0.41 & 0.71 & $0.6 \pm 0.17$ \\
& Horizontal & 0.55 & 0.39 & 0.78 & $0.57 \pm 0.2$ \\
\hline \multirow{2}{*}{5} & Vertical & 0.35 & 0.69 & 0.67 & $0.57 \pm 0.2$ \\
& Horizontal & 0.59 & 0.65 & 0.75 & $0.66 \pm 0.08$ \\
\hline \multirow{2}{*}{6} & Vertical & 0.83 & 0.84 & 0.66 & $0.78 \pm 0.1$ \\
& Horizontal & 0.73 & 0.72 & 0.71 & $0.72 \pm 0.01$ \\
\hline \multirow{2}{*}{7} & Vertical & 0.57 & 0.71 & 0.65 & $0.64 \pm 0.07$ \\
& Horizontal & 0.64 & 0.71 & 0.62 & $0.66 \pm 0.05$ \\
\hline \multirow{2}{*}{8} & Vertical & 0.68 & 0.76 & 0.75 & $0.73 \pm 0.04$ \\
& Horizontal & 0.75 & 0.68 & 0.78 & $0.74 \pm 0.05$ \\
\hline \multirow{2}{*}{9} & Vertical & 0.74 & 0.86 & 0.86 & $0.82 \pm 0.07$ \\
& Horizontal & 0.77 & 0.73 & 0.9 & $0.8 \pm 0.09$ \\
\hline
\end{tabular}

Then, following the criterion "the smaller - the better", the ETA function was determined (Figure 2) according to the formula [12]:

$$
\eta=-10 \cdot \log _{10}\left[\left(\frac{1}{n}\right) \cdot \sum y_{i}^{2}\right],
$$

where $n$-number of tests;

$y_{i}-$ analysed parameter value.
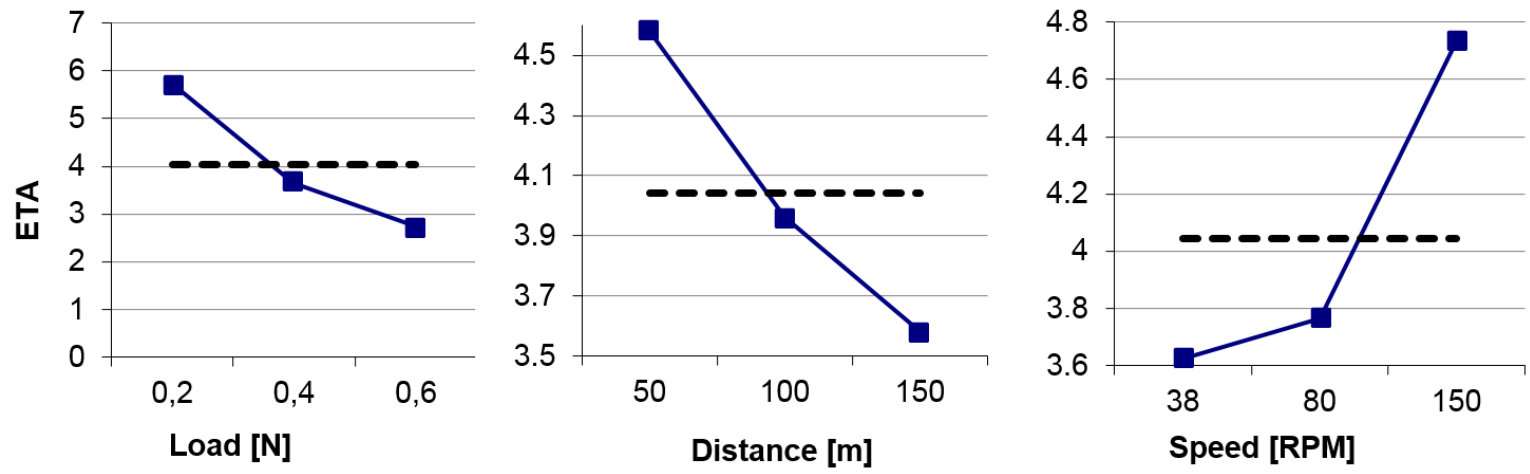

Fig. 2. ETA function

By analyzing the obtained values, the optimal (i.e. giving the most repeatable results) input parameters of the experiment were determined, namely:

- $\quad$ load $-0.6 \mathrm{~N}$;

- $\operatorname{road}-150 \mathrm{~m}$;

- $\quad$ speed-38 RPM. 


\section{Results and discussion}

The subject of the actual tests was a total of 6 samples ( 3 of B27 steel and 3 of 27MnCrB5-2). The direct results of the research were craters formed in the above-mentioned samples (Figures 3 and 4). Crater diameters were measured in two planes, in accordance with PN-EN 1071-6: 2008, using the OLYMPUS SC30 microscope. The results of the crater measurements are summarized in Table 3.

a)

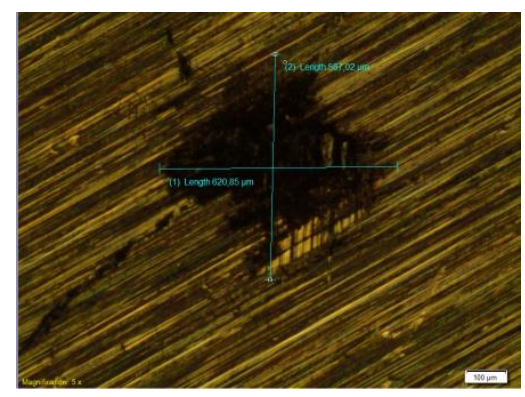

b)

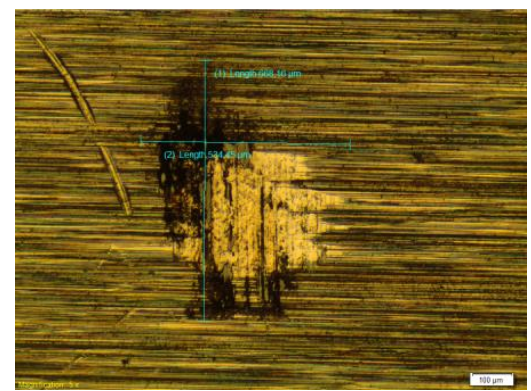

c)

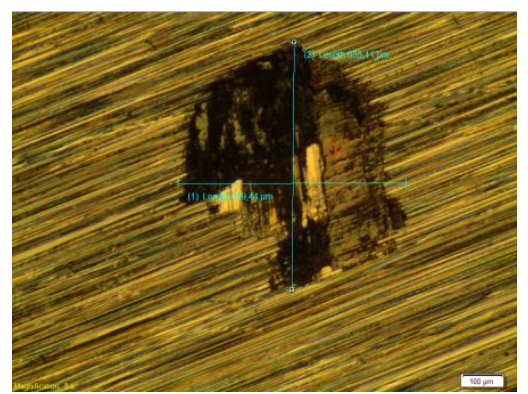

Fig. 3. Research results of 27MnCrB5-2 steel: a- sample No. 1, b- sample No. 2, c- sample No. 3

a)

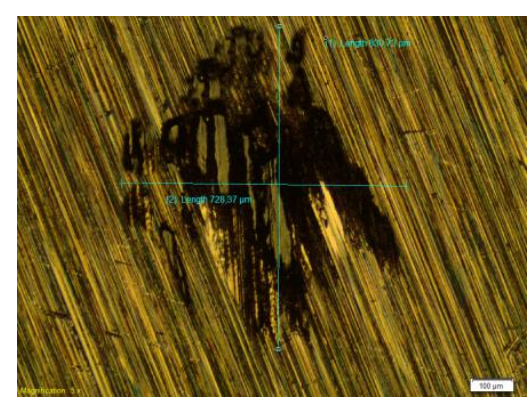

b)

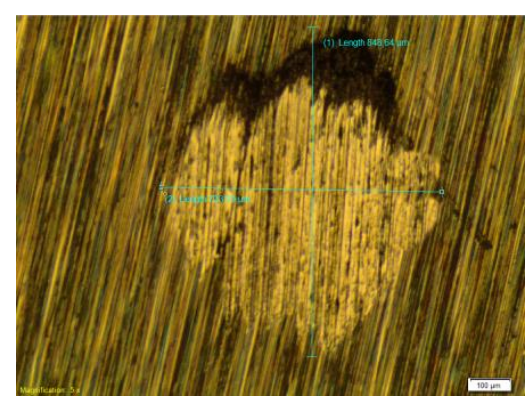

c)

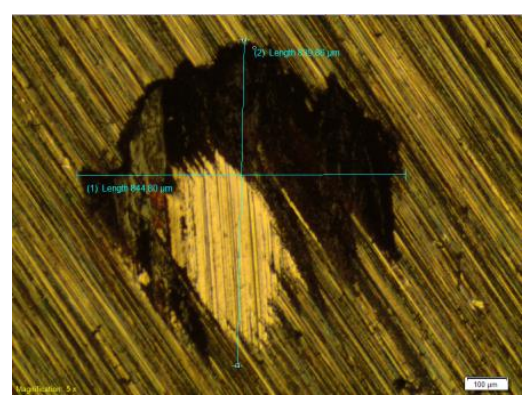

Fig. 4. Research results of B27 steel: a- sample No. 1, b- sample No. 2, c- sample No. 3

Research results

Table 2

\begin{tabular}{|c|c|c|c|c|c|}
\hline Type of steel & $\begin{array}{c}\text { Measuring } \\
\text { Surface }\end{array}$ & $\begin{array}{c}\text { Test result } \\
\text { No. 1, } \boldsymbol{\mu m}\end{array}$ & $\begin{array}{c}\text { Test result } \\
\text { No. 2, } \boldsymbol{\mu m}\end{array}$ & $\begin{array}{c}\text { Test result } \\
\text { No. 3, } \boldsymbol{\mu m}\end{array}$ & $\begin{array}{c}\text { Arithmetic } \\
\text { mean }\end{array}$ \\
\hline \multirow{2}{*}{ 27MnCrB5-2 } & Vertical & 587 & 668 & 638 & $631 \pm 40.95$ \\
& Horizontal & 620 & 534 & 589 & $581 \pm 43.55$ \\
\hline \multirow{2}{*}{ B27 } & Vertical & 830 & 848 & 839 & $839 \pm 9$ \\
& Horizontal & 728 & 723 & 844 & $765 \pm 68.46$ \\
\hline
\end{tabular}

By transforming the Archard equation, the formula for the abrasive wear rate coefficient was obtained [13]:

$$
K_{c}=\pi \frac{b^{4}}{64 \cdot R \cdot S \cdot N}
$$

where $b$-crater diameter, $\mathrm{m}$;

$S$ - distance, m;

$N$ - load, N;

$R-$ ball radius.

After the substitution of arithmetic mean, the following were obtained:

- for $\mathrm{B} 27-K_{c}=5.935 \cdot 10^{-18} \mathrm{~m}^{3} \cdot \mathrm{N}^{-1} \cdot \mathrm{m}^{-1}$,

- for $27 \mathrm{MnCrB5}-2-K_{c}=1.9347 \cdot 10^{-18} \mathrm{~m}^{3} \cdot \mathrm{N}^{-1} \cdot \mathrm{m}^{-1}$. 


\section{Conclusions}

The manuscript proposes a method for assessing the parameters of the material used in the production of plows. Examples of the research results are included for two types of materials: B27 and $27 \mathrm{MnCrB5}-2$ steel. The main goal was to determine the abrasive wear rates of the above-mentioned materials. The obtained results showed that the $27 \mathrm{MnCrB} 5-2$ steel is characterized by approximately three times lower $\mathrm{K}_{\mathrm{c}}$ coefficient, which means that it is three times more resistant to dry abrasion. The conclusion is also confirmed by the size of the craters obtained in the course of the research. Their average diameters for steel B27 were about $25 \%$ larger with the same boundary conditions of the tests.

\section{Funding}

This publication was financed through the program of the Ministry of Science and Higher Education of Poland named "Regional Initiative of Excellence" in 2019-2022 project number 011/RID/2018/19.

\section{Acknowledgments}

This research was co-founded through subsidy of the Ministry of Science and Higher Education for the discipline of mechanical engineering at the Faculty of Mechanical Engineering, Bialystok University of Technology WZ/WM-IIM/4/2020.

\section{References}

[1] Askari M., Shahgholi G., Abbaspour-Gilandeh, Y. New wings on the interaction between conventional subsoiler and paraplow tines with the soil: Eects on the draft and the properties of soil. Arch. Agron. Soil Sci., vol. 65, 2018, pp. 88-100.

[2] Bulgakov V., Adamchuk V., Nadykto V., Kistechok O., Olt, J. Theoretical research into the stability of motion of the ploughing tractor-implement unit operating on the 'push-pull' principle. Agron. Res. vol. 15, 2017, pp. 1517-1529.

[3] Abbaspour-Gilandeh M., Shahgoli G., Abbaspour-Gilandeh Y., Herrera-Miranda M.A., Hernández-Hernández J.L., Herrera-Miranda I. Measuring and Comparing Forces Acting on Moldboard Plow and Para-Plow withWing to Replace Moldboard Plow with Para-Plow for Tillage and Modeling It Using Adaptive Neuro-Fuzzy Interface System. Agriculture, vol. 10, 2020, 633.

[4] Akbarnia A., Mohammadi A., Farhani F., Alimardani, R. Simulation of draft force of winged share tillage tool using artificial neural network model. Agric Eng. Int., vol. 16, 2014, pp. 57-65.

[5] Dexter A.R., Czyz O.P., Gat E. A method for soil penetration resistance. Soil Till. Res., vol. 93, 2007, pp. 412-419.

[6] Harrison H., Licsko Z. Soil reacting forces for models of three bentleg plows. Soil Tillage Res., vol. 15, 1989, pp. 125-135.

[7] Godwin R., Reynolds A., O’Dogherty M., Al-Ghazal A.A. Triaxial Dynamometer for Force and Moment Measurements on Tillage Implements. J. Agric. Eng. Res., vol. 55, 1993, pp. 189-205.

[8] Hayhoe H.N., Lapen D.R., McLaughlin N.B., Curnoe, W. E. Measurement of mouldboard plow draft: I. Spectrum analysis and filtering. Precision Agriculture, vol. 3, 2002, 225-236.

[9] Girma, G. Dynamic effects of speed, depth and soil strength upon forces on plough components. Journal of Agricultural Engineering Research, vol. 51, 1992, pp. 47-66.

[10] Kuczewski, J. Soil parameters for predicting the draught of model plough bodies. Journal of Agricultural Engineering Research, vol. 26, 1981, pp. 193-201.

[11] Borawski A. Suggested Research Method for Testing Selected Tribological Properties of Friction Components in Vehicle Braking Systems. Acta Mechanica et Automatica, vol. 10(3), 2016, pp. 223-226.

[12] Borawski A. Common methods in analysing the tribological properties of brake pads and discs - a review. Acta Mechanica et Automatica, vol. 13(3), 2019, pp. 189-199.

[13] Borawski A., Szpica D., Mieczkowski G. Verification tests of frictional heat modelling results, Mechanika, vol. 26, 2020, pp. 260-264, 